\title{
Local Air Quality Management policy and practice in the UK: the case for greater Public Health integration and engagement
}

\author{
Brunt $H^{a, b}$, Barnes $J^{a}$, Longhurst JWS ${ }^{a}$, Scally $G^{c}$, Hayes $E^{a}$, \\ ${ }^{a}$ Air Quality Management Resource Centre, University of the West of England, Bristol, UK \\ ${ }^{b}$ Environmental Public Health Team, Public Health Wales, Cardiff, UK \\ ${ }^{c}$ WHO Collaborating Centre for Healthy Urban Environments, University of the West of England, Bristol, UK
}

\begin{abstract}
The UK's Local Air Quality Management (LAQM) regime is designed to protect people's health from the ill-effects of air pollution, but it is failing to achieve its full potential. The Public Health aspects of, perspectives on, and integration and engagement in, LAQM have been poorly considered to date. This critical literature review assessed LAQM-related strengths and limitations in order to explore how Public Health, through greater integration and engagement, can add value to the regime.

'Structure' and 'process' weaknesses were identified, including: a poorly defined Public Health role, a narrowly-scoped prescribed process, risk assessment uncertainties, ineffective communications, shallow evaluations and disconnected policies. Separately and cumulatively, these have hindered Public Health integration in LAQM policy and practice and stunted the regime's evolution. Engaging Public Health in LAQM future design and delivery can help solve these problems, by improving risk assessments and raising awareness of air pollution and other health-influencing relationships, targeting action in high-need areas, coordinating air pollution mitigation and health improvement interventions, and connecting different policy areas.

Increasing Public Health integration and engagement in LAQM can enhance the existing regime. Acting now is timely from both LAQM and Public Health perspectives. This review's findings should be used to inform debates and decisions around the future development of local air quality management arrangements both in the UK and beyond.
\end{abstract}

Keywords: $\quad$ Local Air Quality Management, Air pollution, Public Health 


\section{Background}

Exposure to air pollution is a significant determinant of health (World Health Organization, 2015; Lim et al., 2012); it reduces life expectancy by increasing mortality and morbidity risks from heart disease and strokes, respiratory diseases, lung cancer and other effects (World Health Organization, 2013). In the UK, the health burden is substantial; around 29,000 deaths and 307,000 lost life-years (Gowers et al., 2014), and 23,500 deaths and 277,000 lost life-years (Department for Environment, Food and Rural Affairs, 2015a), are attributed annually to $\mathrm{PM}_{2.5}$ and $\mathrm{NO}_{2}$ exposure, respectively. On average, the life expectancy of every person is reduced by 7-8 months (Department for Environment, Food and Rural Affairs, 2007).

Despite general UK air quality improvements, problems persist, especially at the local level - as evidenced by the declaration of some 620 Air Quality Management Areas (AQMAs) across 250 (62\%) UK Local Authorities (as of April 2015) (Department for Environment, Food and Rural Affairs, 2015b). Consequent local-level health impacts vary considerably, not only influenced by differential air pollution exposures but also by individual and population-level susceptibilities (Lipfert, 2004). The triple jeopardy of air pollution, impaired health and social deprivation can compound problems by creating disproportionate and amplified disease burdens between and within regions (Goodman et al., 2011; Jerrett et al., 2001).

Effective air quality management must therefore be based on a good understanding of local air pollution problems and solutions in a broad public health context (Bowen, 2002). In the UK, the Local Air Quality Management (LAQM) regime provides the framework to support collaborative action to assess and reduce local air pollution problems to protect health. Despite its intentions and underpinning principles, the Public Health aspects of, perspectives on, and level of integration in, the LAQM regime have been poorly considered to date.

This paper critiques available literature to assess LAQM-related strengths and weakness, and explore ways in which Public Health, through greater integration and engagement, can add value to the process. This review is likely to be relevant beyond the UK context.

\subsection{UK Local Air Quality Management}

LAQM originates in the 1997 National Air Quality Strategy (Department of the Environment, 1997) and Part IV of the 1995 Environment Act (HM Government, 1995). The National Air Quality Strategy outlined a consistent UK approach to air quality management, committed to ensuring access for all citizens to outdoor air without significant health risk (Department of the Environment, 1997). National policy measures were to tackle larger-scale issues such as vehicle fuel quality, engine technology standards and emissions from combustion processes, but most of the air quality improvement task falls to Local Governments. This recognised that pollution sources are best managed at the lowest administrative level through proportionate, collaborative action that takes account of the local context (Department of the Environment, Transport and the Regions, 2000).

The Strategy stated that health should be protected from the effects of air pollution through national and local-level action to comply with Air Quality Objectives (AQOs) for key air pollutants: benzene, 1,3-butadiene, carbon monoxide, lead, nitrogen dioxide, ozone, particulate matter $\left(\mathrm{PM}_{10}\right)$ and sulphur dioxide. AQOs (specified in the UK Air Quality Regulations (HM Government, 1997) and modified by UK Devolved Administrations and European Air Quality Limit Values (European Council, 1999) were set at levels below which effects are unlikely (even in sensitive groups) or exceedingly small. LAQM is concerned with seven of these pollutants; the secondary formation and transboundary characteristics of ozone place its management beyond the remit of LAQM. 
Since 1997, relevant European Air Quality Directives have been consolidated as the European Ambient Air Quality Directive 2008/50/EC (European Parliament, 2008), three revisions of the UK National Air Quality Strategy have been published (the latest iteration being the Air Quality Strategy for England, Scotland, Wales and Northern Ireland (Department for Environment, Food and Rural Affairs, 2007)) and the UK Air Quality Regulations have been updated (HM Government, 2010). Through LAQM, resources (including monitoring network developments, data collection and collation and modelling techniques, policy and technical guidance and expert 'helpdesks') have been made available to facilitate process implementation and enhance Local Government expertise, capabilities and capacity.

Despite some process-reporting streamlining and modifications of AQO timescales, values and/or exceedence limits, LAQM's two-stage effects-based approach (i.e. air quality assessment in the context of likely public exposure) has remained largely unchanged since its inception (Longhurst et al., 2009; Barnes et al., 2014) (Fig. 1). Undertaken in periodic cycles, LAQM's two stages are:

i. Review and Assessment: a phased risk-management approach to review air quality in locations where the public is likely to be regularly present constitutes Updating and Screening Assessment. If AQO breaches are confirmed or likely (determined by monitored or modelled data) and the exposure duration is appropriate to the averaging period of pollutant(s) AQO(s), a Detailed Assessment and Air Quality Management Area (AQMA) declaration is required. As a minimum, AQMAs should define the area of technical exceedence.

ii. Action Planning: following AQMA declaration, Local Governments must develop and implement an Air Quality Action Plan (AQAP) of collaborative, proportionate, cost-effective and time-bound mitigation and management measures. In these areas, Local Governments must work towards achieving specified AQOs. Further Assessments test the validity of the AQMA declaration and provide further evidence (e.g. source apportionment) and quality assurance to support AQAPs.

Fig. 1. Overview of the two-stage LAQM process (as of July 2015).

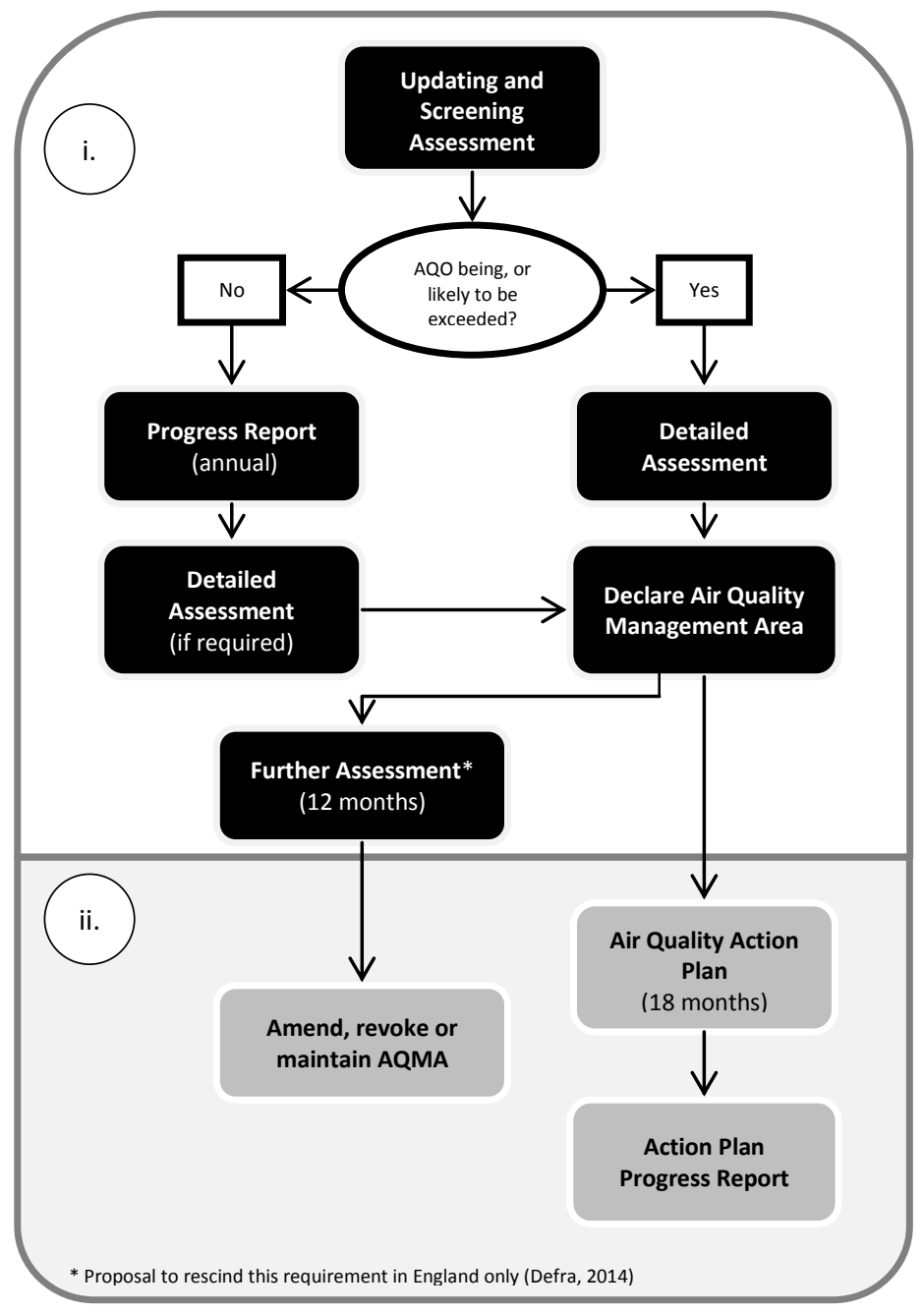




\subsection{The Public Health role}

Public Health is 'the science and art of promoting and protecting health and well-being, preventing ill-health and prolonging life through organised efforts of society' (Faculty of Public Health, 2010). Practice is scientific insofar as it requires rigorous, evidence-based approaches to protect and improve population health based on critical understandings of disease patterns, distributions and causes (including links with wider health determinants) and knowledge of what works to bring about change. The art of Public Health refers to harnessing social, political, economic and cultural societal assets to facilitate collaboration around common causes (Riordan, 2015).

Working across health protection, health improvement and health service quality domains (with health intelligence support) Public Health agencies have core responsibilities that can support the design and delivery of LAQM (Table 1). This paper proposes that the tailored application of these can enhance the LAQM process. No matter how Public Health is structured or where located, e.g. whether embedded in Local Government (England) or in the NHS (Wales, Scotland and Northern Ireland), the type of support that can be offered to LAQM is consistent throughout the UK, although it is accepted that the level of support may vary.

Table 1. Public Health responsibilities (adapted from Donaldson and Scally, 2009; and Harrell and Baker, 1994).

- Monitor health status to identify community health problems

- Diagnose and investigate community health problems and hazards

- Inform, educate and empower people about health issues

- Mobilise communities to identify and solve health problems

- Develop and implement policies/interventions to protect and improve health

- Enforce laws and regulations that protect health

- Link people with services and ensure the provision of needs-based health services

- Ensure a competent public health workforce

- Evaluate the effectiveness, accessibility and quality of public health services/interventions

- Conduct research to identify innovative solutions to health problems

- Use evidence to advocate for change through strategic leadership

\section{Methods}

Peer-reviewed papers were identified by searching electronic journal databases and Google Scholar (1993-2015) using independent and combined terms: "local air quality management", "air pollution", "public health", "integration", "collaboration", "policy", "review", "assessment" and "evaluation". A Google search identified grey literature reports, articles and other non-academic documents. Papers were selected for review if they featured any aspect of the UK LAQM regime. Papers that made reference to Public Health links with air quality management processes in a broader, non-LAQM-specific context, were also eligible for review.

To lend structure and rigour, the review adopted a 'whole-system' approach through the application of an adapted Donabedian evaluation framework (Donabedian, 2005; Donabedian, 1980). In the context of LAQM, this model required simultaneous assessments of 'structure', 'process' and 'outcome' measures and an exploration of relationships between them, where:

i. 'structure' referred to the context in which the LAQM regime is delivered, organisation characteristics, physical and human resources, training, finance, equipment and intelligence;

ii. 'process' covered the interaction between stakeholders to deliver the LAQM regime, technical processes, actions taken and the manner in which they are taken; 
iii. 'outcome' described the effects of the LAQM regime: air quality and population health impacts, organisational or population behaviour changes as a result.

Although this framework has traditionally been used to assess healthcare service quality (e.g. primary care ( $\mathrm{Ng}$ and $\mathrm{Ng}, 2013$ ), midwifery (de Bruin-Kooistra et al., 2012); eye-care (Sheen et al., 2009)), its flexibility has meant that it has also supported evaluations of non-clinical public health programmes (e.g. oral-health (Ahn et al., 2011), smoking cessation (Farmer et al., 2011), exercisereferral (Brunt, 2006), nutrition (Glanz et al., 2005)).

\section{Results}

Of the seventy-seven peer-reviewed papers identified through the search, a total of fifty-eight met the criteria for inclusion in the review. Forty-eight of these were LAQM-specific and a further ten were eligible for review through reference to air quality management/Public Health issues in non-UK countries. An additional seven grey-literature reports were identified that met criteria for review.

From this literature, a critique of LAQM's Public Health-related strengths and weaknesses follows, set in the context of the regime's 'structure', 'process' and 'outcome' measures. However, some source-evidence quality context is first required. It should be noted that much of the LAQM-specific literature was authored by a small group of researchers which may have introduced some bias into the available literature. However, because LAQM is a specialist subject and researchers working in this area possess specialist knowledge and technical expertise, they are, inevitably, few in number. The peer-reviewed research was mostly based on case-studies where empirical research methods were clearly defined, transparent and repeatable. Mixed findings suggested that publication bias was negligible, but selection bias was evident in some source-literature where 'success stories' were over-reported (e.g. Laxen et al., 2013). The grey-literature reported data from questionnaire surveys which are prone to bias (despite response rates being above 40\%); it is of note that the five LAQM reviews identified were undertaken and/or commissioned by UK Government which may have influenced participator responses. However, for each, documented steps were taken to introduce independence e.g. the survey that informed the IHPC review was administered and analysed independently by academics on behalf of the UK Government (e.g. Hayes et al., 2009).

\subsection{LAQM 'structure' measures}

\section{Approach and design}

The LAQM regime's main strength originates from the UK's model of air quality management making a distinction between 'national' and 'local' action. It acknowledges that local air pollution problems can impact local public health, and are best managed locally (Welsh Government, 2009). This may be a weakness too; devolving air pollution management responsibilities to local agencies might have downplayed the importance of air quality as a public health priority (Carmichael and Lambert, 2011; Longhurst et al., 2009). The divide between national and local air quality management agendas (due mainly to a mismatch between local and national designated areas and little requirement for local problems to feature in UK-European reports) may also have contributed (Hayes et al., 2009).

In terms of design, LAQM has strong underpinning Public Health principles. At its core is the concept of risk assessment; Review and Assessment requires that local air pollution problems are considered in the context of pragmatic AQOs based on clear health-based standards (see Department for Environment, Food and Rural Affairs, 2009). Action Planning calls for coordinated, evidence-based intervention (with cost-benefit assessments of both environmental and health considerations) accompanied by progress assessment and evaluation reporting. The logical and structured prescribed framework of LAQM, and its statutory status, supports an approach to air quality review 
and assessment that is uniform and consistent (Chatterton et al., 2007). However, despite these positives, the LAQM process design is too centrally-driven, cumbersome and process-heavy, with excessive reporting requirements and bureaucracy (In-house Policy Consultants, 2010). Of most concern is that the Public Health roots and underpinning principles identified by Chatterton et al. (2007) rarely inform and influence the implementation of LAQM in practice.

Scopelt is suggested that LAQM's health effects-based approach is narrow in scope (Everard et al., 2013), but the literature does not elaborate on this. From a Public Health perspective, despite expectations described in Government guidance (e.g. Welsh Government, 2009), LAQM's narrow and inflexible approach fails to prescribe the consideration of local air pollution problems in a broad public health context. As it stands, LAQM Review and Assessment requires no quantification of local air pollution-related disease burdens or assessments of air pollution relationships and interactions with other local health determinants, to inform decisions and actions. Evidence like this is needed to prioritise and target action according to health needs, and identify opportunities to link air pollution management and wider public health action. But, the task of generating such evidence presents challenges; partners must commit to share local health, air pollution and other data, and Public Health and air pollution risk assessment expertise is required to link, analyse and interpret data.

To date, the usefulness of such 'big picture' evidence has largely been ignored by LAQM. This means it is difficult to work to the principle that the largest public health benefits will result not from simply reducing air pollution, but by doing so in areas where health needs are greatest (Jerrett et al., 2001). Indeed, acting to manage local air pollution problems and protect health on a limited understanding of scope and relationships, or worse, ignoring them altogether, may actually compound problems through poorly-informed, ill-conceived decisions and actions (Bowen, 2002).

\section{Adaptability}

LAQM has questionably been described as a dynamic process reflecting developments in legislative, technology and scientific advances (Chatterton et al., 2007). It is true that the regime has been updated to reflect $A Q O$ amendments set out in legislation that provide the statutory basis for the AQOs under the LAQM system, but such updates have not gone far enough (Department for Environment, Food and Rural Affairs, 2013).

For example, concerns continue to grow that the UK-level health-based standards upon which LAQM risk assessment and action hinges, are insufficiently protective of health. Evidence confirms that exposure to $\mathrm{PM}_{2.5}$ (Beelen et al., 2014; Cesaroni et al., 2014) and nitrogen dioxide (World Health Organization, 2013) at concentrations below current European limit values can result in measurable adverse health impacts. In terms of $\mathrm{PM}_{2.5}$, AQOs commit to address exposure problems, but due to the pollutant's characteristics, the approach to its management is through UK-wide 'exposure reduction' akin to Rose's classical prevention paradox (Rose, 1981) where reductions in overall mean background pollution levels on a wider spatial scale increase the potential for greater public health benefits (Longhurst et al., 2009). Despite there being an appetite to formally report on $\mathrm{PM}_{2.5}$ in LAQM (Hayes et al., 2009), Local Governments are currently not required to work towards the achievement of $\mathrm{PM}_{2.5}$ objectives as part of their LAQM role since it is largely a trans-boundary pollutant and beyond the scope of LAQM, but also because $\mathrm{PM}_{10}$ mitigation will help reduce $\mathrm{PM}_{2.5}$ levels. So, there remains a need to tighten European and UK air quality health standards further to ensure that the health-based standards used in LAQM reflect the Government's view on acceptable health risk (Longhurst et al., 2006). Ideally, for LAQM, any changes must be accompanied by a statutory obligation to comply with AQOs rather than the existing requirement to merely work towards achieving them. On a more positive but less technical note, the LAQM process has demonstrated it can adapt to stakeholder feedback; processes have been streamlined to reduce administrative/reporting burdens. 
Public Health role and development

Public Health, as an LAQM stakeholder, has much to offer. Whilst this has been recognised (Laxen et al., 2013; In-house Policy Consultants, 2010; Welsh Government, 2009; Defra, 2007; Longhurst et al., 2006; Beattie et al., 2001), little attempt has been made to clarify or specify Public Health's role in, and expected contribution to, the regime. This is surprising given that Lindley et al. (1996) noted Public Health opportunities and began to specify this role prior to the formal establishment of LAQM. This is a significant failing that has likely contributed to the development of a disconnect between the two agendas and hindered the evolution of a Public Health-focused LAQM model.

In contrast to Local Government, who have taken advantage of LAQM resource provision (developing human resource, structural and asset-based capabilities and expertise to assess air quality locally using sophisticated monitoring and modelling techniques (Woodfield et al., 2003)), Public Health has generally failed to develop expertise, resources and capacity in air quality assessment and management. This may be due in part to LAQM guidance and resources being Local Government-specific, too technical for non-air quality specialists and tailored to the needs of Local Governments, but also perhaps because of issues identified in this review. Problems have discouraged Public Health engagement in LAQM, with many (especially Public Health 'generalists') lacking necessary knowledge, skills and confidence to support LAQM. This may have resulted in Public Health professionals failing to regard air pollution as a local public health priority and realise their role in its assessment and management.

\subsection{LAQM 'process' measures}

\section{Professional co-ordination, consultation and collaboration}

The diversity of air pollution problems and solutions dictates that collaboration in air quality management is critical (Longhurst et al., 1996). As such, LAQM (usually co-ordinated by Local Government Environmental Health Departments) encourages stakeholder cooperation, collaboration and policy/action co-ordination. To help, Local Government roles (Environmental Health, Planning, Transport, Economic Development and Climate Change) have been described, along with those of external bodies like Environmental Regulators and agencies responsible for road networks (Welsh Government, 2009). But this has had little impact on levels of inter-

departmental/agency collaboration; relatively few examples of good LAQM collaboration (such as multiagency Air Quality Action Plan development) have been reported (Olowoporoku et al., 2012; Hayes et al., 2009; Woodfield et al., 2006; Beattie et al., 2000). The literature agrees there is a lack of support for LAQM from policy agendas other than Environmental Health (Department for Environment, Food and Rural Affairs, 2013). Certainly, any collaboration has been mostly within and between Local Government organisations, rather than with external agencies (In-house Policy Consultants, 2010).

Only one paper referred to Public Health being involved in Air Quality Action Plan Steering Groups, and that reported limited engagement (Hayes et al., 2009). Generally, there has been little dialogue LAQM-related collaboration between Local Governments and Public Health (Leksmono et al., 2010). Public Health is disengaged from the process (Longhurst et al., 2006). Although it is plausible that the problems raised in this critique have contributed to this situation, there is a lack of evidence to support this; LAQM-related reviews have, to date, focused on exploring interactions across and between Local Government organisations, rather than seeking to assess relationships with external agencies. Public Health has been largely ignored. To illustrate the point: one major Government review commented that "the whole purpose of LAQM is to protect public health, and air pollution needs to be considered in the context of what is known about its health impacts and how these compare with other public health risks", but the review team actually failed to consult Public Health 
(In-house Policy Consultants, 2010). This is also true of other formal LAQM consultations (e.g. Welsh Government, 2009).

\section{Communication}

Another possible consequence of poor links with Public Health is the observation that effective communications to improve public understanding around local air quality issues are lacking (Dorfman et al., 2010; Leksmono et al., 2010; McDonald et al., 2002). A survey undertaken to assess public perception of air pollution found that whilst the public are generally aware of health problems associated with exposure, most could not understand and relate their own experiences to much of the science behind air quality assessment and policy (McDonald et al., 2002). This may explain why the public tend to feel unable to engage in, or influence, local circumstances. To compound problems, even where understanding is good, those living in disadvantaged areas feel less empowered and able to do anything about it (Day, 2007).

General air pollution and health communications (not tailored to local characteristics) tend to imply that that any linked health risks and impacts are evenly distributed across areas/populations; they often disguise that substantial impacts may be suffered by a vulnerable minority (IHPC, 2010) e.g. highly-deprived people living alongside major roads, suffering greater adverse health impacts through increased susceptibility. As such, air pollution and health messages need to be carefullycrafted, contextualised and conveyed authoritatively (In-house Policy Consultants, 2010). Concerns have been raised that some Local Government organisations are ill-equipped to communicate complex public health messages on their own (Barnes et al., 2014). With Public Health disengaged from LAQM, Local Governments struggle to communicate health messages with expertise and authority (Beattie et al., 2001).

This is of concern since a greater public understanding of local air pollution causes and solutions could lead to behaviour changes that reduce air pollution and benefit health (House of Commons Environmental Audit Committee, 2009). A lack of public understanding about local air pollution problems is not only detrimental in this regard, but reduces public engagement and increases opposition to new policies. As observed in the rejection of Manchester and Edinburgh congestioncharging schemes (House of Commons Environmental Audit Committee, 2009), policy development is stunted when politicians are reluctant to introduce publically-contentious policies (Bannister, 2008).

\section{Public engagement}

Public Health is not unique in being disengaged from LAQM; local communities are too (Beattie et al., 2001); this is problematic give that community-based participation can play an important role in documenting and understanding health concerns and inequities, and fostering corrective action. If the public are aware of local problems, and understand causes and solutions, there is an increased likelihood that they can assist by cooperating and taking ownership, providing valuable local knowledge and context, and becoming more informed, empowered and willing to take and promote behaviour-modifying action (Cannibal and Lemon, 2000). Through such behaviour changes, local air quality and health co-benefits can result, but these 'win-win' situations will only be realised if public consultation and communication mechanisms are effective, implemented early and highlight some actual or perceived public benefit (e.g. health gain) (Leksmono et al., 2010). Public Health agencies often have strong links with community networks and so could also contribute. 


\section{3}

LAQM 'outcome' measures

\section{Review and Assessment}

The sound, repeatable and efficient characteristics of LAQM's Review and Assessment have reportedly strengthened air quality assessment science and helped generate a comprehensive picture of local-level air pollution across the UK (Longhurst et al., 2009; Chatterton et al., 2007; Longhurst et al., 2006; Beattie et al., 2001). Whilst this statement may be reflective of the process, confidence in the practical implementation and outputs of risk assessments is much lower. There are concerns that LAQM air pollution monitoring and modelling methods have been inconsistently applied and, at times, public air pollution exposure insufficiently considered (Woodfield et al., 2003). Even simple metrics such as numbers of people living within AQMAs, as requested by LAQM Policy and Technical Guidance (Welsh Government, 2009; Department for Environment, Food and Rural Affairs, 2009), have been inconsistently reported.

These concerns may have compromised abilities to identify geographies and populations affected by unacceptably high levels of air pollution with confidence. From a Public Health perspective, this is entirely unhelpful since risk assessment outputs inform AQMA decision-making, declarations and boundary setting (Woodfield et al., 2006). In turn, this influences the extent to which LAQM's requirement for air quality and health impact assessment can be met. Not only is it rare for AQMA boundary-setting decisions to take into account baseline population health profiles (to inform subsequent evaluations), but there is no consistency in AQMA boundary-setting across the UK. AQMAs vary in size, from single dwellings or road junctions to entire towns/boroughs (Longhurst et al., 2009; Chatterton et al., 2004). Further, AQMA boundaries are often incompatible with administrative boundaries (which determine the collection and analysis of health and other data); evaluating the public health impacts of air quality management interventions is thus enormously challenging. Considering local air pollution problems in a broader public health context and allowing local population health profiles to influence AQMA boundaries would help address this problem but, again, Public Health expertise is needed to support this process.

\section{Action Planning}

Although still recognised as an essential LAQM component (Department for Environment, Food and Rural Affairs, 2013), LAQM Action Planning has, to date, been ineffective (Longhurst et al., 2009). On the whole, air pollution reduction interventions have been weak; few cases of air quality improvements have resulted from action with even fewer instances of AQMAs being revoked (Chatterton et al., 2007).

Cost-effective air pollution mitigation can result from an integrated approach that delivers across multiple policy agendas. For example, measures to promote active travel (e.g. walking and cycling) over vehicle use contribute towards meeting public health, air quality and climate change targets. One review (in London) identified that the benefit-to-cost return on such interventions was substantial: $£ 620$ in benefits for every $£ 100$ spent (Kilbane-Dawe, 2012). However, evidence of intervention effectiveness is limited (Everard et al., 2013). This is because of the challenges in establishing the required reliable systems for tracking both air quality and health outcomes data (Matte et al., 2009). Again, this is unhelpful since policy development should be informed; it is important to know what actions, and in what combination(s), will have what results (Policy Exchange, 2013). Not only could increased Public Health integration deliver more effective and efficient action, but also present opportunities to target broader public health action in polluted areas to improve baseline health status and reduce individual and population-level susceptibility. 


\section{Policy connection}

The literature provides evidence that LAQM is not sufficiently supported by relevant policy areas. This has been assessed and corroborated on many occasions, both generally (Department for Environment, Food and Rural Affairs, 2013; House of Commons Environmental Audit Committee, 2011; In-house Policy Consultants, 2010) and from policy-specific perspectives e.g. climate change (Baldwin et al., 2009) and transport planning (Olowoporoku et al., 2012). The latter assessment of LAQM and local transport planning process connections in England, and linked research, revealed that policy integration facilitated better cooperation (Olowoporoku et al., 2012; Olowoporoku et al., 2011; Olowoporoku et al., 2010). Equivalent Public Health-related assessments have not been carried out.

The success of the LAQM regime is dependent upon establishing strong, cross-cutting, reciprocal and sustainable links between air pollution management and other policy areas. Integrating policy in this way is believed to increase the potential for multiple and diverse 'wins' across policy areas (Everard et al., 2013; Stern, 2006). However, the benefits of air pollution reduction, although real, may not be as immediately obvious as the costs (Farber, 2013). Convincing policy-makers to invest in air quality management is challenging, but it appears that local Air Quality Strategies (currently not required by LAQM) have helped Local Governments raise the profile of air pollution and connect policy.

It is logical to assume that identifying and making connections with wider Public Health policy will improve the design and delivery of LAQM. Doing this just because air pollution exposure is linked with ill-health though is not sufficient. It is also necessary to raise the profile of air pollution as a local public health priority, encourage local collaboration with Public Health, consider local air pollution problems and solutions in the context of wider determinants of health, identify shared priorities, and act more effectively and efficiently to achieve greater levels of health gain. At the national level, calls have been made for greater cooperation across air quality and Public Health agendas (House of Commons Environmental Audit Committee, 2014; Policy Exchange, 2013). Missing opportunities to replicate this locally will only serve to inhibit LAQM development and delivery and widen the disconnect.

\section{Discussion}

The Public Health aspects of, perspectives on, and integration in, LAQM have been largely ignored, but this critique has helped develop a better understanding of the inter-relationships of these.

The regime is failing to achieve its full potential as a result of several LAQM 'structure' and 'process' weaknesses (Fig. 2). Although described previously as a strong example of a public health-oriented environmental management programme (Longhurst et al., 2009), it is clear that this is inadequate. Rather, LAQM should be Public Health-driven with action not only triggered and informed by local air quality assessments but also by local air pollution-related public health needs assessments, and also where Public Health can be part of the solution.

The weaknesses discussed have likely hindered Public Health integration in LAQM policy and practice and stunted the regime's evolution. Some - particularly the poorly defined Public Health role and narrow prescribed process - have created a situation where Local Governments fail to routinely consult and collaborate with Public Health because it is not specifically prescribed in the process, and Public Health fails to engage and contribute because they are not aware, sufficiently skilled, or routinely invited to do so by Local Governments. The scope of this phenomenon across the UK is unknown, but it is reasonable to conclude that increasing Public Health integration and engagement in LAQM can help solve identified problems and add value to the existing process (Fig. 2).

Specifically: 
- Review and Assessment - sharing and interpreting health data and evidence of population health-needs would support and improve risk assessments by ensuring they frame local air pollution problems in a broader public health context to inform decisions, priority-setting and targeted action. In turn, this could improve risk communications which, through new channels such as Director of Public Health annual reports (Department for Environment, Food and Rural Affairs, 2013), would be more meaningful, authoritative and accessible. The profile of air pollution as a local public health priority would be raised amongst agencies and the public. Consequently, raised public awareness and engagement could prompt behaviour change that reduces pollution levels, minimises exposures and improves baseline health status to reduce susceptibility to the effects of air pollution.

- Action Planning - action targeted in areas where the greatest health gain can be achieved would become more focused, co-ordinated and impactful. Air pollution mitigation (particularly action resulting in air quality and health co-benefits) could be implemented simultaneously by Local Government organisations and Public Health with increased efficiency and effectiveness. Wider Public Health interventions could also be targeted in polluted areas to improve baseline health status. AQMA boundary-setting influenced by health data collection methods would support intervention evaluations (of air and health impacts) to determine 'what works' in practice.

More generally, given the broad range of issues Public Health professionals are interested in, it would also be possible to recognise opportunities to advocate for, and provide authority, leadership and autonomy to bring about, evidence-based change through policy connection/development.

Fig. 2. LAQM and Public Health problems, solutions and added value.

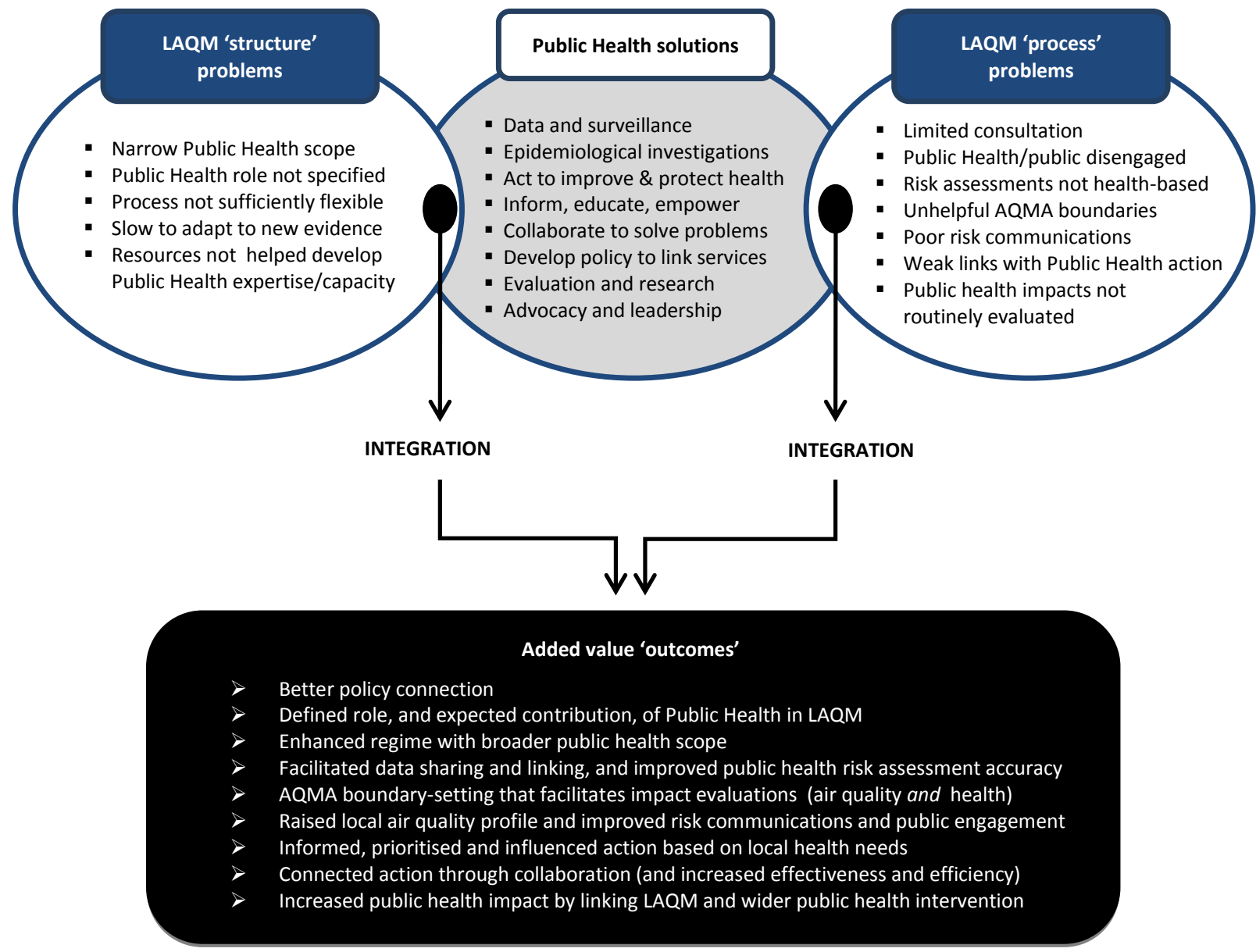


If LAQM is to remain the framework of choice to manage local air quality, and there is certainly the appetite for this and for Public Health principles to continue to underpin it (In-house Policy Consultants, 2010), then change is needed now. It has been suggested that, in the absence of LAQM, there would be no local incentive or pressure to sufficiently support local action to improve air quality; if the process is removed (with current increasing economic pressures on Local Governments) local air quality assessment and management activities may be cut or even disbanded (Department for Environment, Food and Rural Affairs, 2013).

Public Health and Local Governments must commit to work together and invest in action to reduce local air pollution problems. Bringing about these changes has the potential to not only improve air quality, lower health risks and inequalities and improve quality of life, but also to reduce the burden on Local Government and Health services ultimately. Defining the Public Health role in LAQM and broadening process scope to require risk assessments and action based on local air pollution problems in the context of broader health needs should be prioritised. These changes are likely to act as a catalyst to achieve the added value described above.

Acting now to bring about such change in the UK is timely from both LAQM and Public Health perspectives:

- The LAQM regime remains the only mechanism through which local public health can be protected by air quality management actions; it is essential that the process is inclusive, efficient and effective. But, even if the LAQM regime in its current guise is abandoned in years to come, there will still be a need for some form of effective tool to manage air quality at the local level. The findings of this critical review will therefore remain relevant.

- Not only is LAQM at a crossroads, so too is Public Health (more specifically the National Health Service (NHS)). In the UK, the NHS recognises it has operated a 'factory-model' of care and repair with a poor track record of community and stakeholder engagement and underdeveloped advocacy, action and policy to address broader influences of health and wellbeing (National Health Service, 2014). Change is required to forge closer, sustainable relationships with partner agencies and communities, develop new ways of working and place more emphasis on disease prevention by tackling major public health risks. As the Chief Medical Officer in Wales recognises, air pollution problems must be regarded as one such risk (Welsh Government, 2014).

This UK situation is not unique. Other countries face similar challenges to integrate Public Health and local air quality management policy and practice. For example, a divide between Governmental environmental management and health departments in South Africa, and an ambiguity in roles, has led to poor local air quality management-related collaboration and health-risk communications (Naiker et al., 2012). In China, Government departments continue to debate how to develop an effective air quality management regime which emphasises the need to understand air pollutionrelated health impacts and take informed, integrated action at the local and regional levels to deliver and measure co-benefits (Wang and Hao, 2012; Fang et al., 2009). These countries, and many others, can benefit from the findings of this review despite its focus on the UK LAQM experience. Some points raised here may be more-readily transferrable to places with existing air quality models similar to UK LAQM (such as South Africa, New Zealand and United States (Longhurst et al., 2009)) or where air quality management development is in its infancy and there are real opportunities to shape it. However, regardless of air quality management arrangements, Public Health structure and cultural, social, economic and political characteristics, because the principles of preventing and controlling air pollution and the core functions of Public Health agencies are broadly similar worldwide, this critique has global relevance. 


\section{Conclusion}

The Public Health aspects of, perspectives on, and integration in, LAQM have received little attention. This critique has moved understanding on by identifying the LAQM and Public Healthrelated 'structure' and 'process' weaknesses that have prevented LAQM deliver effective 'outcomes'.

As direct or indirect consequences of weaknesses identified, opportunities to integrate and engage Public Health in LAQM have been missed. Acting to bridge this disconnect would enhance policy design at the national level and its practical application locally. Whilst Public Health agencies and professionals are unable to single-handedly reduce air pollution levels in problem areas, their possible contribution to assessment and management processes is significant. Integrating Public Health in LAQM would help realise opportunities to solve the problems highlighted in this review and add value through: increased engagement and collaboration, improved risk assessment by understanding local air pollution problems in a broader context, enhanced risk communications, prioritised and targeted health needs-based action (that extends beyond simply reducing air pollution levels), connecting policy and practice, and evaluating intervention effectiveness.

Acting to address these problems now is timely. Debates and discussions around the future development of LAQM in the UK, or any successor regime, should take note of this critique. Despite its focus on LAQM, the findings of this review have relevance beyond the UK.

In light of this review identifying the need for the existing LAQM regime to be Public Health-driven and broader in scope, research is ongoing to assess the added value that could result from considering local air pollution problems and solutions in a wider public health context. Similarly, since it remains unclear why Public Health is not fully integrated and engaged in LAQM, research is also underway to determine what changes are required to enhance existing LAQM policy and practice to bring about changes that make a positive 'real world' difference.

\section{Acknowledgements}

Part-funding for this research has been provided by Public Health Wales. In particular, the authors would like to acknowledge the guidance and support of Dr Marion Lyons, Director of Health Protection at Public Health Wales. 


\section{References}

Ahn S, Burdine JN, Smith LN et al.(2011). Residential rurality and oral health disparities: influences of contextual and individual factors. Journal of Primary Prevention;32(1):29-41.

Baldwin ST, Everard M, Hayes ET et al.(2009).Progress, barriers, opportunities for the co-management of air pollution and carbon emissions in South West England. Air Pollution XVII(86):185-194.

Bannister D(2008). The sustainable mobility paradigm. Transport Policy; 15:73-80.

Barnes JH, Hayes ET, Chatterton TJ, Longhurst JWS(2014). Air quality action planning: why do barriers to remediation in local air quality management remain? Journal of Environmental Planning and Management;57(5):660-681.

Beelen R, Raaschou-Nielsen O, Stafoggia M, et al.(2014). Effects of long-term exposure to air pollution on natural-cause mortality: an analysis of 22 European cohorts within the multicentre ESCAPE project. Lancet;383:785-795.

Beattie $\mathrm{Cl}$, Longhurst JWS, Woodfield NK(2000). Air quality management: challenges and solutions in delivering air quality action plans. Energy and Environment;11(6):729-747.

Beattie $\mathrm{Cl}$, Longhurst JWS, Woodfield NK(2001). Air quality management: evolution of policy and practice in the UK as exemplified by the experience of English local government. Atmospheric Environment;35:1479-1490.

Bowen W(2002). An analytical review of environmental justice research: what do we really know? Environmental Management;29(1):3-15.

Brunt $\mathrm{H}(2006)$. An evaluation of the health and wellbeing aspects of the Swansea 'Positive Steps' exercise referral scheme, September 2004 to March 2006. Swansea:NPHS.

Cannibal G, Lemon M(2000). The strategic gap in air quality management. Journal of Environmental Management; 60(4):289-300.

Carmichael L, Lambert C(2011). Governance, knowledge and sustainability: the implementation of EU directives on air quality in Southampton. Local Environment;16(2):181-191.

Cesaroni G, Forastiere F, Stafoggia M et al.(2014). Long term exposure to ambient air pollution and incidence of acute coronary events: prospective cohort study and meta-analysis in 11 European cohorts from the ESCAPE Project. BMJ;348:f7412.

Chatterton TJ, Woodfield NK, Beattie Cl, Longhurst JWS(2004). Outcomes of the first round of local authority air quality Review and Assessments under the UK's air quality strategy. Journal of Environmental Monitoring;6:849-853.

Chatterton T, Longhurst J, Leksmono N et al.(2007). Ten years of Local Air Quality Management experience in the UK: an analysis of the process. Clean Air and Environmental Quality;41(4):26-31.

Day R(2007). Place and the experience of air quality. Health and Place;13:249-260.

Department for Environment, Food and Rural Affairs(2007). The Air Quality Strategy for England, Scotland, Wales and Northern Ireland (vol 1/2). London:Defra.

Department for Environment, Food and Rural Affairs(2009). Local Air Quality Management Technical Guidance TG(09). London:Defra.

Department for Environment, Food and Rural Affairs(2013). Local air quality management review summary of responses and government reply. London:Defra.

Department for Environment, Food and Rural Affairs(2014). Review of Local Air Quality Management: consultation on regulatory and guidance changes. London:Defra.

Department for Environment, Food and Rural Affairs(2015a). Draft plans to improve air quality in the UK: tackling nitrogen dioxide in our towns and cities. UK overview document. London:Defra.

Department for Environment, Food and Rural Affairs(2015b). Summary AQMA data. Accessed: http://uk-air.defra.gov.uk/aqma/summary 16/07/15.

Department of the Environment, Transport and Regions, Scottish Executive, National Assembly for Wales, Department of Environment for Northern Ireland(2000). The Air Quality Strategy for England, Scotland, Wales and Northern Ireland. CM 4548. London:TSO.

De Bruin-Kooistra M, Amelink-Verburg MP et al.(2012). Finding the right indicators for assessing quality midwifery care. International Journal for Quality in Health Care; DOI: http://dx.doi.org/10.1093/intahc/mzs006

Department of the Environment(1997). The United Kingdom National Air Quality Strategy. London:TSO. 
Donabedian A(1980). The definition of quality and approaches to its assessment. Health Administration Press:Ann Arbor.

Donabedian A(2005). Evaluating the quality of medical care. The Millbank Quarterly;83(4):691-729. Donaldson L, Scally G(2009). Donaldson's Essential Public Health $3^{\text {rd }}$ edition. London:Radcliffe Press. Dorfman P, Gibbs DC, Leksmono NS et al.(2010). Exploring the context of consultation. Case of Local Air Quality Management. Local Environment;15(1):15-26.

European Council(1999). Directive 1999/30/EC relating to limit values for $\mathrm{SO}_{2}, \mathrm{NO}_{2}$ and $\mathrm{NOx}$ particulate matter and lead in ambient air. Brussels European Council.

European Parliament(2008). Directive 2008/50/EC of the European Parliament and of the Council on ambient air quality and cleaner air for Europe. Brussels:European Parliament.

Everard M, Pontin B, Appleby T et al.(2013). Air as a Common Good. Env Sci and Policy;33:354-368.

Faculty of Public Health(2010). What is Public Health practice? Accessed: http://www.fph.org.uk/what is public health 16/07/15.

Fang M, Chan CK, Yao X (2009). Managing air quality in a rapidly developing nation: China.

Atmospheric Environment; 43:79-86.

Farber HJ(2013). Public policy, air quality and protecting most vulnerable. CHEST;144(4):1093-1094.

Farmer MM, Rose DE, Ropelle D et al.(2011). Gender differences in smoking and smoking cessation treatment: an examination of the organizational features related to care. Women's Health Issues; 21(4):182-189.

Glanz K, Sallis JF, Saelens BE et al.(2005). Healthy nutrition environments: concepts and measures. American Journal of Health Promotion;19(5):330-333.

Goodman A, Wilkinson P, Stafford M, Tonne C(2011). Characterising socioeconomic inequalities in exposure to air pollution: a comparison of socio-economic markers and scales of measurement. Health \& Place;17:767-774.

Gowers AM, Miller BG, Stedman JR(2014). Estimating local mortality burdens associated with particulate air pollution. London:Public Health England.

Harrell JA, Baker EL(1994). Essential services of public health. Leadership Public Health; 3(3):27-30.

Hayes E, Chatterton T, Laxen D(2009). Questionnaire survey of UK Local Authorities on the Local Air Quality Management Process. Bristol:UWE/AQC.

HM Government(1995). Environment Act 1995, Chapter 25 (part IV). London:HMSO.

HM Government(1997). Air Quality Regulations, 1997,3043. London:HMSO.

HM Government(2010). Air Quality Standards Regulations. London:HMSO.

House of Commons Environmental Audit Committee(2009). Memorandum submitted by LA Coordinators of Regulatory Services. Accessed:

http://publications.parliament.uk/pa/cm200910/cmselect/cmenvaud/229/229we16.htm, 16/07/15.

House of Commons Environmental Audit Committee(2011). Fifth Report of Session 2009-10.

London:House of Commons.

House of Commons Environmental Audit Committee(2014). Action on Air Quality. Sixth report of session 2014-15. London:TSO.

In House Policy Consultants (IHPC)(2010). Review of Local Air Quality Management: report to Defra and the Devolved Administrations. London:Defra.

Jerrett M, Burnett R, Kanaroglou P, et al.(2001). A GIS-environmental justice analysis of particulate air pollution in Hamilton, Canada. Environment and Planning A;33:955-973.

Kilbane-Dawe I(2012). Cost Effective Actions to Cut Central London Air Pollution. London:Par Hill Research Ltd.

Laxen D, Beattie C, Dickie I (2014). Health impacts of air pollution in Bristol. Bristol: Air Quality Consultants.

Leksmono N, Dorfman P, Burnet F et al.(2010). Enhancing consultation practices in Air Quality Management in local authorities. Journal of Env Planning and Management;53(5):559-571.

Lim SS, Vos T, Flaxman AD et al.(2012). A comparative risk assessment of burden of disease and injury attributable to 67 risk factors and risk factor clusters in 21 regions, 1990-2010: a systematic analysis for the Global Burden of Disease Study 2010. Lancet;380:2224-2260. 
Lindley SJ, Longhurst JWS, Watson AFR, Conlan DE(1996). Procedures for estimation of regional scale atmospheric emissions-an example from NW region of England. Atmos Env;30(17):3079-3091.

Lipfert FW(2004). Air pollution and poverty: does the sword cut both ways? J Epi Com Health;58:2-3.

Longhurst JWS, Lindley SJ, Watson AFR, Conlan DE(1996). The introduction of local air quality management in the UK. A review and theoretical framework. Atmospheric Env.;30(23):3975-3985.

Longhurst JWS, Beattie $\mathrm{Cl}$, Chatterton TJ et al.(2006). Local air quality management as a risk management process: Assessing, managing and remediating risk of exceeding an air quality objective in Great Britain. Environment International;32:934-947.

Longhurst JWS, Irwin JG, Chatterton TJ et al.(2009). The development of effects-based air quality management regimes. Atmospheric Environment;43:64-78.

Matte TD, Cohen A, Dimmick F et al.(2009). Summary of the workshop on methodologies for environmental public health tracking air pollution effects. Air Qual Atmos Health;2(4):177-184.

McDonald JS, Hession M, Rickard A et al.(2002). Air quality management in UK local authorities: public understanding and participation. J Env Planning and Management;45(4):571-590.

Naiker Y, Diab RD, Zunckel M, Hayes ET (2012). Introduction of local Air Quality Management in South Africa: overview and challenges. Journal of Environmental Science and Policy;17:62-71.

National Health service(2014). NHS England - Five-year forward view. Accessed: https://www.england.nhs.uk/wp-content/uploads/2014/10/5yfv-web.pdf, 16/07/15.

$\mathrm{Ng}$ CWL, Ng KP(2013). Does practice size matter? Review of effects on quality of care in primary care. British Journal of General Practice. DOI:10.3399/bjgp13X671588.

Olowoporoku AO, Hayes ET, Leksmono NS et al.(2010). A longitudinal study of links between LAQM and local transport planning policy processes in England. Journal of Environmental Planning and Management;53(3):385-403.

Olowoporoku AO, Hayes E, Longhurst J, Parkhurst G(2011). Improving road transport-related air quality in England through joint working between Environmental Health and Transport Planners. Local Environment;16(3):603-618.

Olowoporoku AO, Hayes E, Longhurst J, Parkhurst G(2012). Rhetoric and realities of integrating air quality into the local transport planning process in English local authorities. J Env Mgt;101:23-32.

Policy Exchange(2013). Cleaning up road transport in London: the next steps to improve the capital's air quality. Accessed:

http://www.policyexchange.org.uk/images/publications/cleaning\%20up\%20road\%20transport\%20in \%20london.pdf, 16/07/15.

Riordan $\mathrm{P}(2015)$. Improving the health of everyone in Wales-the Public Health challenge of prudent healthcare. Accessed: http://www.prudenthealthcare.org.uk/wp-

content/uploads/2014/10/Improving-the-health-of-everyone-in-Wales-\%E2\%80\%93-the-publichealth-challenge-of-prudent-healthcare.pdf, 07/10/15.

Rose G(1981). Strategy of prevention:lessons from cardiovascular disease. BMJ;282:1847-51.

Sheen NJL, Fone D, Phillips CJ et al. (2009). Novel optometrist-led all-Wales primary eye-care services: evaluation of prospective case series. British Journal of Ophthalmology;93(4):435-438.

Stern N(2006). Stern review: the economics of climate change. Accessed:

http://webarchive.nationalarchives.gov.uk/20130129110402/http://www.hmtreasury.gov.uk/stern review report.htm, 16/07/15.

Wang S, Hao J (2012). Air quality management in China: issues, challenges and options. Journal of Environmental Sciences;24(1):2-13.

Welsh Government(2009). Local Air Quality Management Policy Guidance for Wales. Cardiff:WG Welsh Government(2014). CMO Wales Annual Report 2013/14. Cardiff: WG.

World Health Organization(2013). Review of evidence on health aspects of air pollution-REVIHAAP. Copenhagen:WHO.

World Health Organization(2015). Economic cost of the health impact of air pollution in Europe: Clean air, health and wealth. Copenhagen:WHO.

Woodfield NK, Longhurst JWS, Beattie Cl, Laxen DPH(2003). Critical evaluation of the role of scientific analysis in UK local authority AQMA decision-making. Science Total Environment;311:1-18. Woodfield NK, Longhurst JWS, Beattie Cl et al.(2006). Regional collaborative urban air quality management: case studies across Great Britain. Environmental Modelling and Software;21:595-599. 